\title{
Skrining Gangguan Dengar pada Pekerja Salah Satu Pabrik Tekstil di Bandung
}

\author{
Yussy Afriani Dewi, Ratna Anggraeni Agustian \\ Departemen Ilmu Kesehatan Telinga, Hidung, Tenggorok, Bedah Kepala dan Leher \\ Fakultas Kedokteran Universitas Padjadjaran-Rumah Sakit Dr. Hasan Sadikin Bandung
}

\begin{abstract}
Abstrak
Pabrik tekstil di Indonesia merupakan sumber devisa yang penting untuk negara karena jumlahnya yang cukup banyak. Para pekerja pabrik mempunyai risiko tinggi untuk terjadinya gangguan dengar. Bunyi dengan intensitas yang cukup kuat $(>85 \mathrm{~dB}$ ) dalam waktu yang cukup lama dapat menyebabkan hilangnya pendengaran, baik sementara maupun tetap. Bila hal ini tidak mendapatkan perhatian yang serius maka dapat mengakibatkan dampak yang tidak diinginkan. Hal ini tidak sesuai dengan tujuan pembangunan kesehatan bangsa Indonesia, Garis-garis Besar Haluan Negara 1998 dalam Pelita IV yang mengarahkan untuk meningkatkan derajat kesehatan masyarakat dan kualitas sumber daya manusia serta usia harapan hidup. Tujuan penelitian untuk mengetahui prevalensi gangguan dengar yang terjadi serta jenis dan derajat ketulian pada pekerja di salah satu pabrik tekstil di Majalaya kabupaten Bandung Jawa Barat. Subjek berjumlah 109 orang pekerja terdiri atas 47 orang laki-laki dan 62 orang perempuan yang dipilih secara total sampling, mulai tanggal 26 Agustus sampai 9 September 2004 dengan penelitian bersifat deskriptif potong lintang. Dilakukan anamnesis dengan pengisian kuesioner, pemeriksaan fisis telinga, dan pemeriksaan audiometri nada murni. Hasil penelitian menunjukkan prevalensi gangguan dengar pada laki-laki $68,1 \%$ lebih banyak bila dibandingkan dengan perempuan $37,2 \%$. Jenis gangguan dengar terbanyak akibat bising $41 \%$ kemudian gangguan dengar tipe sensori-neural $32 \%$, tipe konduktif $23 \%$, dan tipe campuran $4 \%$. Prevalensi derajat gangguan dengar ringan 46,8\%; sedang 3,7\%; dan berat $0,9 \%$. Simpulan, gangguan dengar yang sering ditemukan pada pekerja pabrik yaitu gangguan dengar yang diakibatkan oleh bising. [MKB. 2012;44(2):96-100].
\end{abstract}

Kata kunci: Gangguan dengar, pekerja pabrik tekstil

\section{Hearing Test Screening at One of the Textile Factory Workers in Bandung}

\begin{abstract}
Textile factory in Indonesia is an important source of foreign exchange for the country because the numbers were quite a lot. The factory workers have a high risk for the occurrence of hearing disorders. Sound intensity more than $85 \mathrm{~dB}$ in a long time could cause hearing loss, both temporary or permanent. If this does not get serious attention, it can results in adverse effects. It is not in accordance with the objective of the development of Health of Indonesia, Outlines of State Policy 1998 to improve community health status and quality of human resources and life expectancy. The objective of this study was to determine the prevalence, degree and type of hearing loss in one of textile factory workers in Majalaya Bandung West-Java. Subjects were 109 workers, consisted of 47 males and 62 females, chosen by total sampling. Sampling was due in August 26 until September 9, 2004. The study design was descriptive cross-sectional. Data was obtained from anamnesis with questionnaire, otologic examination and pure tone audiometry evaluation. The results showed that hearing loss was more common in male subjects $68.1 \%$ compared to female subjects $37.2 \%$. The most common hearing loss was noise induced $41 \%$, followed by sensorineural $32 \%$, conductive $23 \%$, mixed type hearing loss $4 \%$. The prevalence of mild hearing loss was $46.8 \%$, moderate $3.7 \%$ and severe $0.9 \%$. In conclusion, hearing disorder which is frequently found in the factory workers is noise-induced hearing loss. [MKB. 2012;44(2):96-100].
\end{abstract}

Key words: Hearing loss, textile factory workers

\footnotetext{
Korespondensi: Yussy Afriani Dewi, dr., M.Kes, Sp.THT-KL(K), Departemen Ilmu Kesehatan Telinga, Hidung, Tenggorok, Bedah Kepala, dan Leher Fakultas Kedokteran Universitas Padjadjaran-RS Dr. Hasan Sadikin Bandung, jalan Pasirkaliki 190 Bandung 40161, telepon (022) 2034953-55 Pes.3327, (022) 2034472, Faks. (022) 2040984, e-mail tht_fkup@yahoo.com
} 


\section{Pendahuluan}

Dewasa ini pengembangan kesehatan masyarakat lebih ditekankan pada pemeliharaan kesehatan, oleh karena upaya preventif dan promotif lebih ditingkatkan tanpa mengabaikan upaya kuratif dan rehabilitatif. Dengan demikian, perilaku hidup sehat pada masyarakat merupakan aspek yang penting untuk dikaji.

Hakekatnya pembangunan kesehatan bertujuan meningkatkan sumber daya manusia. Kesehatan pancaindera, terutama kesehatan indera penglihatan serta pendengaran merupakan faktor penting dalam meningkatkan mutu sumber daya manusia karena akan memengaruhi kecerdasan, produktivitas, dan kesejahteraan. ${ }^{2}$

Pendengaran merupakan salah satu dari pancaindera yang digunakan untuk berkomunikasi dan berinteraksi, baik antara sesama manusia maupun dengan lingkungan sekitarnya. Gangguan dengar akan mengurangi kemampuan menerima informasi dan berkomunikasi melalui suara, sehingga akan menyulitkan pelaksanaan pekerjaan. ${ }^{3}$

Sampai dengan tahun 1995, World Health Organization memperkirakan secara kasar bahwa di dunia terdapat \pm 120 juta orang yang mempunyai permasalahan dengan pendengaran yaitu sekitar $2 \%$ dari populasi keseluruhan. Perkiraan angka ini naik pada tahun 2003 yaitu sekitar 240 juta orang, sekitar 78 juta di antaranya berada di negara berkembang. ${ }^{4}$

Penelitian pada tahun 2004 dinyatakan bahwa \pm 28 juta penduduk Amerika Serikat mengalami penurunan ambang pendengaran dan sebanyak $80 \%$ menderita gangguan dengar menetap yang terdiri atas $4,6 \%$ pada usia $18-44$ tahun, $14 \%$ pada usia 45-64 tahun, 54\% pada usia 65 tahun, 23\% pada usia 65-74 tahun, dan $31 \%$ di atas usia 75 tahun. ${ }^{5}$

Berdasarkan survei mengenai kesehatan indera pendengaran dan penglihatan di tujuh provinsi pada tahun 1994-1996 ternyata dari seluruh penyakit telinga hidung tenggorok dan mata, prevalensi penyakit THT sebesar 38\%, 18,5\%-nya merupakan penyakit telinga. ${ }^{1}$

Sebagai negara berbentuk kepulauan, Indonesia mempunyai 5 pulau besar dan lainnya pulau kecil. Menurut sensus nasional total populasi sebesar 205 juta pada tahun 2000 , didapatkan sekitar $16,8 \%$ menderita gangguan pendengaran yang di antaranya ketulian $(0,4 \%))^{5}$

Pabrik tekstil di Indonesia merupakan sumber devisa yang penting untuk negara karena jumlahnya yang cukup banyak. Para pekerja pabrik mempunyai risiko tinggi untuk terjadinya gangguan dengar. Bunyi dengan intensitas yang cukup kuat $(>85 \mathrm{~dB})$ dalam waktu yang cukup lama dapat menyebabkan hilangnya pendengaran, baik sementara maupun tetap. ${ }^{6}$
Bila hal ini tidak mendapatkan perhatian yang serius, maka dapat mengakibatkan dampak yang tidak diinginkan. Hal ini tidak sesuai dengan tujuan pembangunan kesehatan bangsa Indonesia, Garisgaris Besar Haluan Negara 1998 dalam Pelita IV yang mengarahkan untuk meningkatkan derajat kesehatan masyarakat dan kualitas sumber daya manusia serta usia harapan hidup.

Tujuan penelitian untuk mengetahui prevalensi gangguan dengar yang terjadi serta jenis dan derajat ketulian pada pekerja di salah satu pabrik tekstil di Majalaya kabupaten Bandung Jawa Barat.

\section{Metode}

Subjek penelitian para pekerja di salah satu pabrik tekstil di Majalaya kabupaten Bandung Jawa Barat dilakukan selama dua bulan (26 Agustus sampai 9 September 2004)

Gangguan dengar yaitu kasus tuli unilateral (satu sisi telinga), tuli ringan bilateral (kedua sisi telinga), dan tuli sedang bilateral, sedangkan ketulian adalah kasus tuli berat bilateral dan tuli sangat berat bilateral. Pembagian derajat ini berdasarkan pedoman International Standard Organization: ISO R389. ${ }^{1}$

Hasil pemeriksaan audiometri pada gangguan dengar akibat bising menunjukkan penurunan ' $d i p$ ' pada frekuensi $4.000 \mathrm{~Hz}$. Hal ini berbeda dengan presbikusis karena penurunan pendengaran yang mengiringi proses menua. Pada audiogram terlihat gambaran penurunan pendengaran bilateral simetris yang mulai terjadi pada nada tinggi. ${ }^{8}$

Dalam penelitian ini para pekerja pabrik tekstil mendapatkan sumber bising yang berasal dari mesin tekstil dengan kebisingan rata-rata 81-98 dB. Audiometer yang dipakai tipe EB-390/220 V nomor seri 7664 yang dilengkapi dengan earphone tipe audiotone TDH $39+$ enclosed audiocap head set no. 3695 dan vibrator bone conduction tipe B 71 yang telah dilakukan kalibrasi pada tahun 2004. Alat ini berguna untuk mengukur fungsi pendengaran dengan menilai berapa besar intensitas suara melalui hantaran udara dan hantaran tulang pada frekuensi $500,1.000,2.000,4.000$, dan $8.000 \mathrm{~Hz}$. Pemeriksaan audiometri dilakukan di dalam ruangan yang sunyi dengan jarak $50 \mathrm{~m}$ dari jalan utama dan tingkat kebisingan kurang dari $35 \mathrm{~dB}$. Tingkat kebisingan di atas diukur dengan menggunakan Sound Level Meter Kanomax.

\section{Hasil}

Selama periode penelitian di salah satu pabrik tekstil di Majalaya Kabupaten Bandung telah dilakukan pemeriksaan terhadap 109 subjek penelitian berusia 
Tabel 1 Distribusi Lama Karyawan Pabrik

\begin{tabular}{ccc}
\hline $\begin{array}{c}\text { Lama Bekerja } \\
\text { (tahun) }\end{array}$ & n & \% \\
\hline$<1$ & 20 & 18,3 \\
1 & 11 & 10,1 \\
2 & 15 & 13,8 \\
3 & 20 & 18,3 \\
4 & 13 & 11,9 \\
5 & 5 & 4,6 \\
6 & 4 & 3,7 \\
7 & 5 & 4,6 \\
8 & 4 & 3,7 \\
10 & 2 & 1,8 \\
11 & 2 & 1,8 \\
14 & 1 & 0,9 \\
16 & 1 & 0,9 \\
17 & 1 & 0,9 \\
18 & 1 & 0,9 \\
20 & 3 & 2,8 \\
24 & 1 & 0,9 \\
Total & 109 & 100,0 \\
\hline
\end{tabular}

Keterangan: mean $=4,22$ tahun; $\mathrm{SD}=4,879$

\section{5-59 tahun (mean=22,22; $\mathrm{SD}=7,907)$.}

Pekerja perempuan lebih banyak dibandingkan dengan laki-laki dengan rasio 1,3:1. Usia para pekerja pabrik tersebut yang terbanyak 19 tahun untuk laki-laki sebanyak 7 orang $(6,4 \%)$ dan untuk perempuan 17 tahun sebanyak 10 orang $(9,2 \%)$.

Tingkat pendidikan yang terbanyak SLTP sebanyak 59 orang $(54,1 \%)$, SD sebanyak 40 orang $(36,7 \%)$, dan SLTA sebanyak 10 orang $(9,2 \%)$.

Lama bekerja para karyawan pabrik tersebut antara 0 dan 24 tahun dengan mean=4,22 dan $\mathrm{SD}=4,879$. Lama bekerja para karyawan terbanyak sudah bekerja selama 3 tahun dan di bawah 1 tahun,
Tabel 2 Distribusi Keluhan yang Dirasakan oleh Para Pekerja

\begin{tabular}{lrr}
\hline \multicolumn{1}{c}{ Keluhan } & n & \multicolumn{1}{c}{$\%$} \\
\hline Telinga tersumbat & 13 & 11,9 \\
Keluar cairan dari telinga & 4 & 3,6 \\
Penurunan pendengaran & 3 & 2,8 \\
Tinitus hilang timbul & 23 & 21,1 \\
Tidak ada keluhan & 66 & 60,6 \\
Total & 109 & 100,0 \\
\hline
\end{tabular}

masing-masing 20 orang (18,3\%) (Tabel 1).

Sebanyak $60,6 \%$ pekerja mengaku tidak mempunyai keluhan dan $21,1 \%$ mengeluh tinitus yang hilang timbul dan bersifat sementara serta hilang dalam 1 jam setelah istirahat (Tabel 2).

Pada pemeriksaan telinga didapatkan telinga normal dengan membran timpani intak yaitu 79,8\% dan $15,6 \%$ tidak dapat dinilai karena terhalang oleh serumen.

Terdapat 56 orang menderita gangguan dengar, terdiri dari 29 orang (52\%) gangguan dengar unilateral dan 27 orang (48\%) gangguan dengar bilateral. Jenis gangguan dengar terbanyak yaitu gangguan dengar akibat bising yaitu 23/56 (41\%). Gangguan dengar yang lain adalah tipe sensorineural sebanyak 32\%, dan tipe konduktif 23\% (Tabel 3).

Derajat gangguan dengar ringan, sedang, dan berat masing-masing $46,8 \% ; 3,7 \%$; dan $0,9 \%$. Para pekerja yang mempunyai pendengaran normal 48,6\% (Tabel 4).

Berdasarkan jenis kelamin, prevalensi gangguan dengar pada laki-laki lebih tinggi dibandingkan dengan perempuan. Berdasarkan latar belakang pendidikan, prevalensi tertinggi gangguan dengar dijumpai pada kelompok yang berpendidikan SLTP (Tabel 5).

Etiologi gangguan dengar yang terjadi pada para pekerja pabrik tersebut di atas paling banyak disebabkan akibat bising 23/56 (41\%) (Tabel 6).

Serumen mempunyai potensi menyebabkan gangguan dengar sehingga diperlukan tindakan

Tabel 3 Distribusi Jenis Gangguan Dengar

\begin{tabular}{|c|c|c|c|c|}
\hline \multirow{2}{*}{ Jenis Gangguan Dengar } & \multirow{2}{*}{$\begin{array}{c}\text { Unilateral } \\
\mathbf{n}\end{array}$} & \multirow{2}{*}{$\begin{array}{c}\text { Bilateral } \\
\mathbf{n}\end{array}$} & \multicolumn{2}{|c|}{ Total } \\
\hline & & & $\mathbf{n}$ & $\%$ \\
\hline Konduktif & 9 & 4 & 13 & 23 \\
\hline Sensorineural & 10 & 8 & 18 & 32 \\
\hline Campuran & 0 & 2 & 2 & 4 \\
\hline Akibat trauma akustik & 10 & 13 & 23 & 41 \\
\hline Total & $29(52 \%)$ & $27(48 \%)$ & 56 & 100 \\
\hline
\end{tabular}


Tabel 4 Distribusi Derajat Gangguan Dengar

\begin{tabular}{lrc}
\hline $\begin{array}{c}\text { Derajat Gangguan } \\
\text { Dengar }\end{array}$ & n & $\begin{array}{c}\text { Persentase } \\
(\%)\end{array}$ \\
\hline Normal & 53 & 48,6 \\
Ringan & 51 & 46,8 \\
Sedang & 4 & 3,7 \\
Berat & 1 & 0,9 \\
Total & 109 & 100,0 \\
\hline
\end{tabular}

pembersihan serumen atau irigasi. Otitis media yang disertai dengan gangguan dengar harus diobati agar tidak menyebabkan komplikasi.

Pekerja yang memerlukan evaluasi audiometri enam bulan berikutnya sebanyak 37,6\%; harus dilakukan ekstraksi serumen/irigasi $15,6 \%$; yang dirujuk untuk bedah telinga elektif agar dilakukan timpanoplasti 4,6\%; sedangkan para pekerja yang memerlukan pengobatan dan pemakaian alat bantu mendengar hanya $0,9 \%$ serta $40,4 \%$ para pekerja tidak memerlukan tindakan.

\section{Pembahasan}

Secara umum gangguan dengar dibagi atas beberapa tipe yaitu tipe konduktif (conductive hearing loss/ CHL), sensorineural (sensorineural hearing loss/ SNHL), dan tipe campuran antara kedua tipe di atas (mixed hearing loss/MHL). ${ }^{9}$

Tuli konduktif terjadi apabila terdapat gangguan hantaran bunyi sistem konduksi di dalam telinga. Tuli sensorineural terjadi apabila terdapat gangguan fungsi sistem sensoris serta saraf pendengaran, misalnya akibat kerusakan sel-sel rambut dalam koklea, N. VIII, dan pusat pendengaran di korteks

Tabel 5 Prevalensi Gangguan Dengar berdasarkan Jenis Kelamin dan Tingkat Pendidikan

\begin{tabular}{llr}
\hline \multirow{2}{*}{ Variabel } & \multicolumn{2}{c}{ Gangguan Dengar } \\
\cline { 2 - 3 } & $\mathbf{n}$ & $\mathbf{\%}$ \\
\hline Jenis kelamin & & \\
Laki-laki & 33 & 60 \\
Perempuan & 23 & 41 \\
Pendidikan & & \\
Tamat SD & 23 & 41 \\
Tamat SLTP & 29 & 52 \\
Tamat SLTA & 4 & 7 \\
Total & 56 & 100 \\
\hline
\end{tabular}

Tabel 6 Distribusi Etiologi Gangguan Dengar

\begin{tabular}{lc}
\hline \multicolumn{1}{c}{ Etiologi Gangguan Dengar } & Frekuensi \\
\hline Gangguan dengar akibat bising & 23 \\
Otitis media & 6 \\
Presbikusis & 2 \\
Serumen & 17 \\
Tidak diketahui & 8 \\
Total & 56 \\
\hline
\end{tabular}

serebri. Tipe campuran terjadi apabila terdapat gangguan penghantaran bunyi sistem konduksi di dalam telinga tengah dan gangguan sistem saraf pendengaran. ${ }^{9}$

Noise induced hearing loss (NIHL) dan presbikusis termasuk dalam gangguan dengar tipe sensorineural. Kurang pendengaran akibat bising di dalam lingkungan kerja telah dikenal sejak lama. Kebisingan yang terjadi memungkinkan terjadinya NIHL, terutama orang yang berada di lingkungan tersebut. ${ }^{9}$

Bertambahnya usia akan menurunkan fungsi pendengaran (presbikusis) yang pada pemeriksaan audiometri nada murni terlihat sebagai gambaran penurunan pendengaran sensorineural bilateral simetris yang umumnya dimulai pada nada tinggi. ${ }^{9}$

Derajat gangguan dengar dapat diukur dengan cara menghitung pure tone average (PTA) yaitu intensitas pendengaran rata-rata pada frekuensi $500 \mathrm{~Hz}, 1.000 \mathrm{~Hz}$, dan $2.000 \mathrm{~Hz}$ dalam desiBell atau dB (ANSI-1969). Penilaian dilakukan pada masing-masing telinga dan telinga yang lebih baik digunakan untuk menentukan derajat pendengaran. Cara lain untuk menentukan beratnya gangguan dengar yang kini lebih dianjurkan yaitu better ear hearing level (BEHL), hasil intensitas rata-rata yang diukur pada frekuensi $500 \mathrm{~Hz}, 100 \mathrm{~Hz}, 2.000$ Hz, dan $4.000 \mathrm{~Hz} .^{9}$

Dari hasil anemnesis, pemeriksaan fisis, dan audiometri, etiologi gangguan dengar yang terjadi pada para pekerja pabrik tersebut di atas paling banyak disebabkan bising (41\%).

Melihat intensitas kebisingan mesin di tempat bekerja yang berkisar $81-98 \mathrm{~dB}$ dan waktu kerja 8-9 jam/hari, ternyata belum melampaui ambang batas occupational safety and health administration (OSHA) namun para pekerja perlu diberi protektor telinga karena melihat hasil NIHL telah mencapai 41\%. Hal ini diperkuat karena usia para pekerja baru sekitar 15-19 tahun merupakan usia yang rentan terhadap paparan bising dibandingkan dengan usia yang lebih tua. Hal ini sesuai dengan peneliti lain yang menyatakan bahwa golongan usia muda lebih mudah mengalami kerusakan sistem auditorisnya bila terkena paparan bising. ${ }^{7,9,10}$ 
Tindakan yang seharusnya dikerjakan untuk mencegah gangguan dengar antara lain para pekerja dihimbau untuk menggunakan alat-alat proteksi telinga yang memadai sebagai pelindung untuk mencegah paparan langsung dari sumber bising, menghimbau kepada pemilik pabrik tekstil tersebut untuk mengusahakan penggunaan dan pengaturan sistem peredaman suara untuk mesin-mesin yang digunakan dan melakukan pemeriksaan audiometri secara berkala minimal satu tahun sekali pada para pekerja pabrik untuk mendeteksi penurunan pendengaran.

Simpulan, gangguan dengar yang paling sering ditemukan pada pekerja pabrik yaitu gangguan dengar yang diakibatkan bising.

\section{Daftar Pustaka}

1. Depkes Republik Indonesia. Hasil survei kesehatan indera penglihatan dan pendengaran. Jakarta: Depkes RI; 1998.

2. Suwento R. Epidemiologi penyakit THT di 7 provinsi. Presentasi pada pelatihan dokter RS dan puskesmas dalam upaya kesehatan telinga komunitas. Bandung; 2002.

3. Saus GA. A strategic formulation to decrease the number of hearing impaired people in Indonesia. Dalam: Suzuki J, Kobayashi T,
Koga K, penyunting Hearing impairment. Japan: Springer; 2004. hlm. 458-9.

4. Sharma B. Hearing impairmant in Nepal. Dalam: Suzuki J, Kobayashi T, Koga K, penyunting. Hearing impairment. Japan: Springer; 2004. hlm. 70-7.

5. Suwento R. Hearing health infrastructure in Indonesia. Dalam: Suzuki J, Kobayashi T, Koga K, penyunting. Hearing impairment. Japan: Springer; 2004. hlm. 45-8.

6. ISO. Acoustic assessment noise with respect to community response. Edisi ke-1. 1976.

7. Agustian RA. Gangguan dengar akibat bising mesin mobil di ruang praktikum pada siswasiswa STM IV Bandung jurusan mesin selama masa pendidikan [tesis]. Bandung: Universitas Padjadjaran; 2003.

8. Hindarmin H. Hearing loss in elderly. Seminar otologi-audiovestibuler. Bandung; 2005.

9. Candra D. Prevalensi dan pola penurunan pendengaran penderita presbikusis pada penduduk daerah Bandung [tesis]. Bandung: Universitas Padjadjaran; 2007.

10. Hall JW. Assessment of peripheral and central auditory function. Dalam: Bailey BJ, penyunting. Head and neck surgeryotolaryngology. Edisi ke-3. Philadelphia: Lippincott-Williams \& Wilkins; 2001. hlm. 1659-62. 